This is a peer-reviewed, accepted author manuscript of the following article: Grommet, A. B., Hoffman, J. B., Percástegui, E. G., Mosquera, J., Howe, D. J., Bolliger, J. L., \& Nitschke, J. R. (2018). Anion exchange drives reversible phase transfer of coordination cages and their cargoes. Journal of the American Chemical Society, 140(44), 14770-14776. https://doi.org/10.1021/jacs.8b07900

\title{
Anion Exchange Drives Reversible Phase Transfer of Coordination Cages and Their Cargoes
}

\author{
Angela B. Grommet, Jack B. Hoffman, Edmundo G. Percástegui, Jesús Mosquera, Duncan J. \\ Howe, Jeanne L. Bolliger, and Jonathan R. Nitschke* \\ Department of Chemistry, University of Cambridge, Lensfield Road, Cambridge, CB2 1EW, United Kingdom
}

\begin{abstract}
Chemical separations technologies are energetically costly; lowering this cost through the development of new molecular separation methods would thus enable significant energy savings. Molecules could, for example, be selectively encapsulated and separated using coordination cages, which can be designed with cavities of tailored sizes and geometries. Before cages can be used to perform industrially-relevant separations, however, the experimental and theoretical foundation for this technology must be established. Using hydrophobic and hydrophilic anions as stimuli, we show that cages can reversibly transfer many times between mutually immiscible liquid phases, thus transporting their molecular cargoes over macroscopic distances. Furthermore, when two cages are dissolved together, sequential phase transfer of individual cage species results in separation of their molecular cargoes. We present a thermodynamic model that describes the transfer profiles of these cages, both individually and in the presence of other cage species. This model provides a new analytical tool to quantify the hydrophobicity of cages.
\end{abstract}

\section{INTRODUCTION}

Here we demonstrate how coordination cages ${ }^{1-3}$ of varying sizes, shapes,,$^{-8}$ and charge densities (Figure 1a) can shuttle between immiscible liquid phases, transport molecular cargoes, and thus perform chemical separations. Anion exchange drives this reversible phase transfer. By using hydrophobic and hydrophilic anions as stimuli to drive transport across a phase boundary, ${ }^{9}$ precise control is exerted over the physical location of these cages and their molecular cargoes. ${ }^{10}$ The only side products from these separations are solutions of salts, which may be reconcentrated and recycled. Contrary to our intuition, the amounts of anions required to effect the transfer of each cage remained constant over many transfer cycles.

We have also quantified how different cage species display different levels of sensitivity to the same stimuli. When different cages are combined, individual cage species thus undergo sequential phase transfer, separating their molecular cargoes. We have described these phenomena using a new thermodynamic model that has been developed to explain the observed behaviors.

\section{RESULTS AND DISCUSSION}

Counteranions ${ }^{11,12}$ are crucial in determining the solubility preferences of cationic coordination cages. When cages $1^{8+}, \mathbf{2}^{8+}$, and $3^{16+}$ (Figure $1^{13^{-15}}$ are paired with sulfate $\left(\mathrm{SO}_{4}{ }^{2-}\right)$ counterions, ${ }^{16}$ they are soluble in water despite the poor aqueous solubilities of their subcomponents. ${ }^{17}$ These cages become insoluble in water but soluble in organic solvents such as acetonitrile when paired with more hydrophobic anions such as trifluoromethanesulfonate or bis(trifluoromethanesulfonyl)imide. ${ }^{17}$ This trend continued as the hydrophobicity of the anion increases: paired with bulky, hydrophobic anions such as tetrakis[3,5bis(trifluoromethyl)phenyl]borate, coordination cages and other polycationic species can become soluble in nonpolar solvents. ${ }^{18-20}$ Building upon these ideas, we have designed a series of systems in which cationic cages were observed to transfer reversibly between water and ethyl acetate (EtOAc) by means of anion exchange (Figure 1).

To biphasic systems composed of EtOAc and aqueous solutions of $\mathbf{1}\left[\mathrm{SO}_{4}\right]_{4}, \mathbf{2}\left[\mathrm{SO}_{4}\right]_{4}$, or ${ }_{3}\left[\mathrm{SO}_{4}\right]_{8}$, the lithium salt of the bulky, hydrophobic anion tetrakis(pentafluorophenyl)borate $\left(\mathrm{LiB}\left(\mathrm{C}_{6} \mathrm{~F}_{5}\right)_{4}\right)$ was added to promote anion metathesis from $\mathrm{SO}_{4}{ }^{2-}$ to $\mathrm{B}\left(\mathrm{C}_{6} \mathrm{~F}_{5}\right)_{4}{ }^{-}$. The resulting $\mathrm{B}\left(\mathrm{C}_{6} \mathrm{~F}_{5}\right)_{4}{ }^{-}$ salts of cages $\mathbf{1}^{8+}, \mathbf{2}^{8+}$, or $3^{\mathbf{1 6 +}}$ became insoluble in water, soluble in EtOAc, and were observed to transfer from wa- 
ter to the EtOAc layer. Conversely, upon the addition of tetrabutylammonium sulfate $\left(\left(\mathrm{n}^{\mathrm{Bu}_{4}} \mathrm{~N}\right)_{2} \mathrm{SO}_{4}\right)$ to biphasic systems composed of water and $\mathbf{1}\left[\mathrm{B}\left(\mathrm{C}_{6} \mathrm{~F}_{5}\right)_{4}\right]_{8}, \mathbf{2}\left[\mathrm{B}\left(\mathrm{C}_{6} \mathrm{~F}_{5}\right)_{4}\right]_{8}$, or $3\left[\mathrm{~B}\left(\mathrm{C}_{6} \mathrm{~F}_{5}\right)_{4}\right]_{16}$ in EtOAc, the cages underwent reverse anion metathesis to regenerate the $\mathrm{SO}_{4}{ }^{2-}$ salts, undergoing phase transfer from EtOAc into the water layer. Addition of sodium tetrakis[3,5-bis(trifluoromethyl)phenyl]borate also resulted in reversible phase transfer, as discussed in Supplementary Information (SI) sections $\mathrm{S}_{4}, \mathrm{~S}_{5}$, and S9.
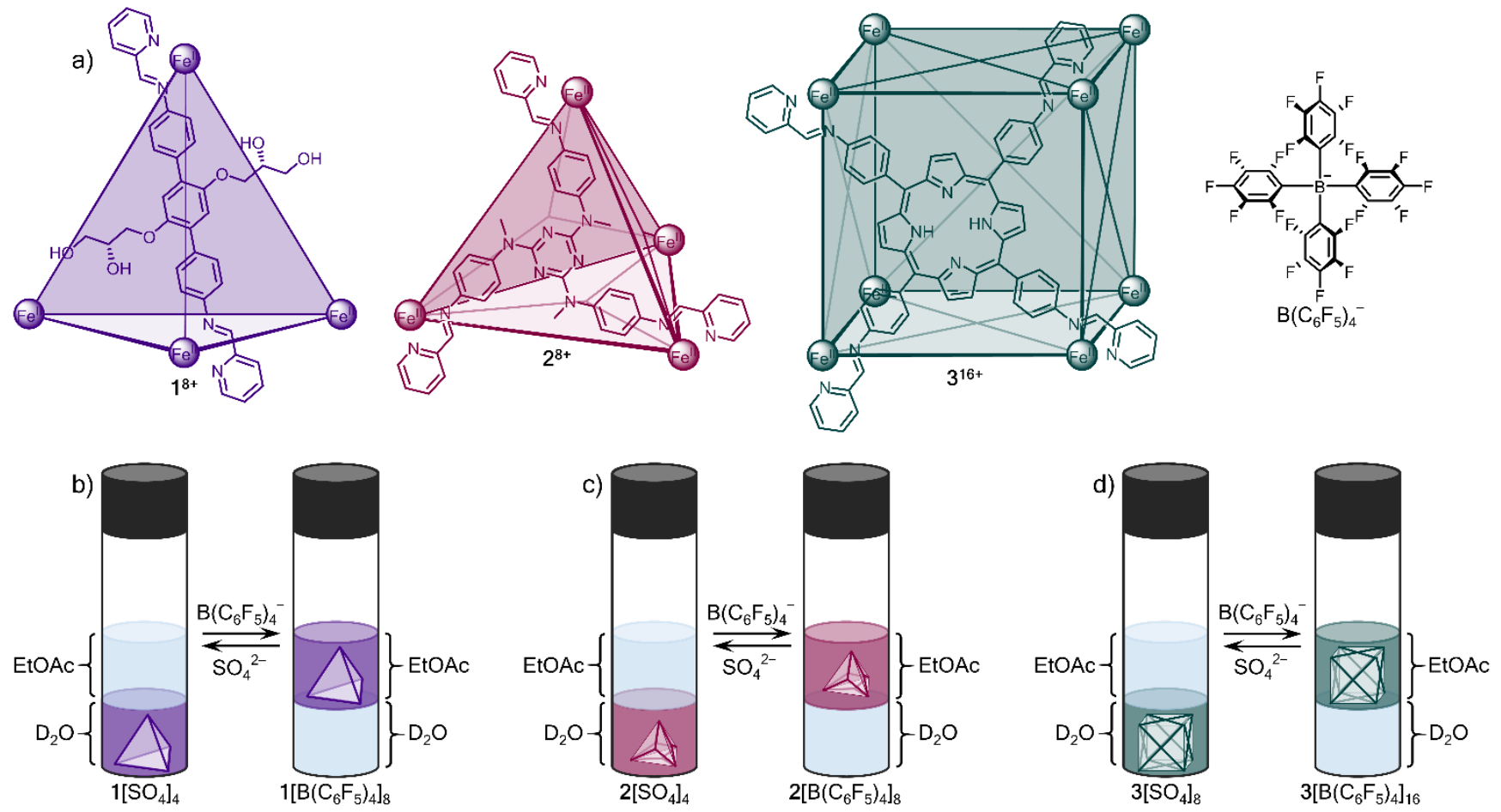

Figure 1. (a) Structural representations of edge-bridged tetrahedral cage $\mathbf{1}^{\mathbf{8}+}$, face-capped tetrahedral cage $\mathbf{2}^{\mathbf{8}+}$, face-caped cubic cage $3^{\mathbf{1 6 +}}$, and anion $\mathrm{B}\left(\mathrm{C}_{6} \mathrm{~F}_{5}\right)_{4}{ }^{-}$. Cage $3^{\mathbf{1 6 +}}$ has a lower charge density than cages $\mathbf{1}^{\mathbf{8 +}}$ or $\mathbf{2}^{\mathbf{8 +}}$. (b-d) Reversible phase transfer of cage $\mathbf{1}^{8+}, \mathbf{2}^{8+}$, and $3^{16+}$ between water and EtOAc following the addition of hydrophobic $\left.\left(\mathrm{B}^{16} \mathrm{C}_{6} \mathrm{~F}_{5}\right)_{4}{ }^{-}\right)$or hydrophilic $\left(\mathrm{SO}_{4}{ }^{2-}\right)$ anions.

Reversible phase transfer of cages $1^{8+}, 2^{8+}$, and $3^{16+}$. To determine the minimal amount of $\mathrm{B}\left(\mathrm{C}_{6} \mathrm{~F}_{5}\right)_{4}{ }^{-}$necessary to effect complete transfer of cages $\mathbf{1}^{8+}, \mathbf{2}^{8+}$, and $3^{16+}$ from water to EtOAc, UV-Vis spectrophotometry was used to monitor the water and EtOAc layers following the addition of $\mathrm{LiB}\left(\mathrm{C}_{6} \mathrm{~F}_{5}\right)_{4}$. Figure $2 \mathrm{a}$ shows the proportion of cage transported as $\mathrm{B}\left(\mathrm{C}_{6} \mathrm{~F}_{5}\right)_{4}{ }^{-}$was added to the system. To effect complete phase transfer into EtOAc, cages $\mathbf{1}^{8+}, \mathbf{2}^{\mathbf{8 +}}$, and $3^{16+}$ all required different amounts of $\mathrm{B}\left(\mathrm{C}_{6} \mathrm{~F}_{5}\right)_{4}^{-}(13$ equiv, 8.2 equiv, and 26 equiv, respectively). To calculate these values, we defined complete transfer to have occurred following the addition of twice the number of anions required to reach the inflection point of the phase transfer profile, and we could detect no further cage in the source phase. We also determined the minimum amount of $\mathrm{SO}_{4}{ }^{2-}$ required to effect reverse transfer of cages $\mathbf{1}^{8+}, \mathbf{2}^{8+}$, or $3^{16+}$ from EtOAc into water. Because $\mathrm{SO}_{4}{ }^{2-}$ possesses twice the negative charge of $\mathrm{B}_{(}\left(\mathrm{C}_{6} \mathrm{~F}_{5}\right)_{4}^{-}$, only half as much $\mathrm{SO}_{4}{ }^{2-}$ as $\mathrm{B}\left(\mathrm{C}_{6} \mathrm{~F}_{5}\right)_{4}^{-}$was required (6.5 equiv, 4.1 equiv, and 13 equiv, respectively). The phase transfer behaviour of cages $\mathbf{1}^{8+}, \mathbf{2}^{8+}$, and $3^{16+}$ was observed to be independent of cage concentration from $5 \mu \mathrm{M}-2 \mathrm{mM}$.
Having determined the minimum amount of anions necessary to complete the transfer of cages $\mathbf{1}^{8+}, \mathbf{2}^{\mathbf{8 +}}$, and $3^{16+}$ between water and EtOAc, we then sought to quantify the reversibility of phase transfer over multiple cycles. To this end we used slice-selective ${ }^{1} \mathrm{H}$ NMR to collect data from both phases within biphasic NMR samples. ${ }^{21,22}$ This experiment provided ${ }^{~} \mathrm{H}$ NMR spectra from $0.5 \mathrm{~mm}$-thick slices centred in the $\mathrm{D}_{2} \mathrm{O}$ layer and the (nondeuterated) EtOAc layer. To streamline NMR analysis, we also developed a program that facilitated the selection of slices. Details of this program are provided in SI section S8.

The use of slice-selective ${ }^{1} \mathrm{H}$ NMR to monitor the phase transfer of cages $\mathbf{1}^{8+}, \mathbf{2}^{8+}$, and $3^{16+}$ allowed us to avoid separating and subsequently recombining the $\mathrm{D}_{2} \mathrm{O}$ and EtOAc layers between additions of hydrophobic or hydrophilic anions. After slice-selective NMR was employed to measure a ${ }^{1} \mathrm{H}$ NMR spectrum from each layer, the minimum amount of $\mathrm{B}\left(\mathrm{C}_{6} \mathrm{~F}_{5}\right)_{4}{ }^{-}$solution was added to achieve complete phase transfer from $\mathrm{D}_{2} \mathrm{O}$ into EtOAc, with this required quantity of anion having previously been determined using UV-Vis. The NMR tube was inverted 20 times, and slice-selective ${ }^{1} \mathrm{H}$ NMR was used to measure 
spectra in both layers. The minimum required amount of $\mathrm{SO}_{4}{ }^{2-}$ was then added to trigger phase transfer of the cage species from EtOAc into $\mathrm{D}_{2} \mathrm{O}$, and both layers were again analysed using slice-selective ${ }^{1} \mathrm{H}$ NMR.

No increase in the number of equivalents of $\mathrm{B}\left(\mathrm{C}_{6} \mathrm{~F}_{5}\right)_{4}{ }^{-}$or $\mathrm{SO}_{4}{ }^{2-}$ added was necessary to achieve complete transport, even after many cycles. Notably, negligible fatigue was observed, even after the cage species had crossed the $\mathrm{D}_{2} \mathrm{O} /$ EtOAc interface 11 times (representative data for cage $\mathbf{2}^{\mathbf{8 +}}$ are presented in Figure $2 b$; data for cages $\mathbf{1}^{8+}$ and $3^{16+}$ can be found in the SI, Figures $\mathrm{S}_{5} 5$ and S67). Because $\mathrm{B}\left(\mathrm{C}_{6} \mathrm{~F}_{5}\right)_{4}{ }^{-}$and $\mathrm{SO}_{4}{ }^{2-}$ were added as stock solutions in EtOAc and $\mathrm{D}_{2} \mathrm{O}$, respectively, the system could not become saturated with salts.

Thermodynamic model describing the reversible phase transfer of cages $1^{8+}, 2^{8+}$, and $3^{16+}$. Using data obtained from the UV-Vis experiments, we developed a thermodynamic model to quantify the parameters that govern phase transfer. This model is grounded upon the assumption that cage solvation in water or EtOAc is associated with the different average energy states, $E_{\text {water }}$ and a)

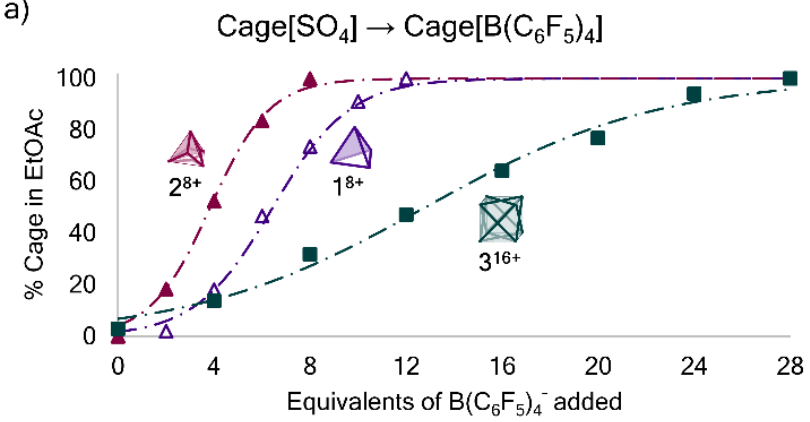

b)

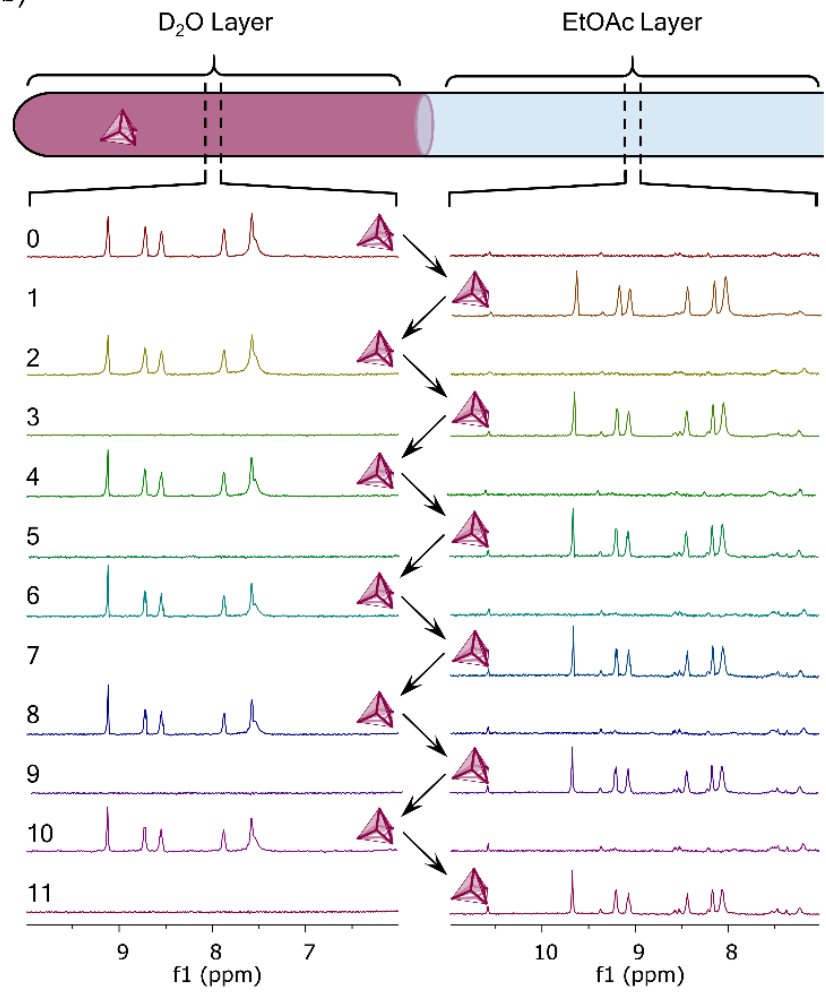

Figure 2. (a) Proportion of cage transport from $\mathrm{D}_{2} \mathrm{O}$ to EtOAc as a function of the amount of anion added to the system. Data were fit to equation (1). (b) Slice-selective ${ }^{1} \mathrm{H}$ NMR data from the $\mathrm{D}_{2} \mathrm{O}$ and EtOAc layers of a single NMR sample as anion exchange (between $\mathrm{SO}_{4}{ }^{2-}$ and $\left.\mathrm{B}\left(\mathrm{C}_{6} \mathrm{~F}_{5}\right)_{4}{ }^{-}\right)$was employed to transport cage $\mathbf{2}^{8+}$ across the phase boundary 11 times.

$E_{\mathrm{EtOAc}}$, respectively. We define $E_{\mathrm{EtOAc}}-E_{\text {water }}$ as $\Delta E$. The partitioning of cage cations between the two layers occurs under thermodynamic control and is therefore described by the Boltzmann distribution over a two-level system, according to Equation (1):

$$
P=\frac{1}{1+e^{\frac{\Delta E}{k T}}}=\frac{1}{1+e^{\frac{m x+\Delta E_{0}}{k T}}}
$$

where $k$ is the Boltzmann constant, $T$ is absolute temperature, and $P$ is defined as the proportion of cage in EtOAc:

$$
P=\frac{n_{\mathrm{EtOAc}}}{n_{\mathrm{water}}+n_{\mathrm{EtOAc}}}
$$



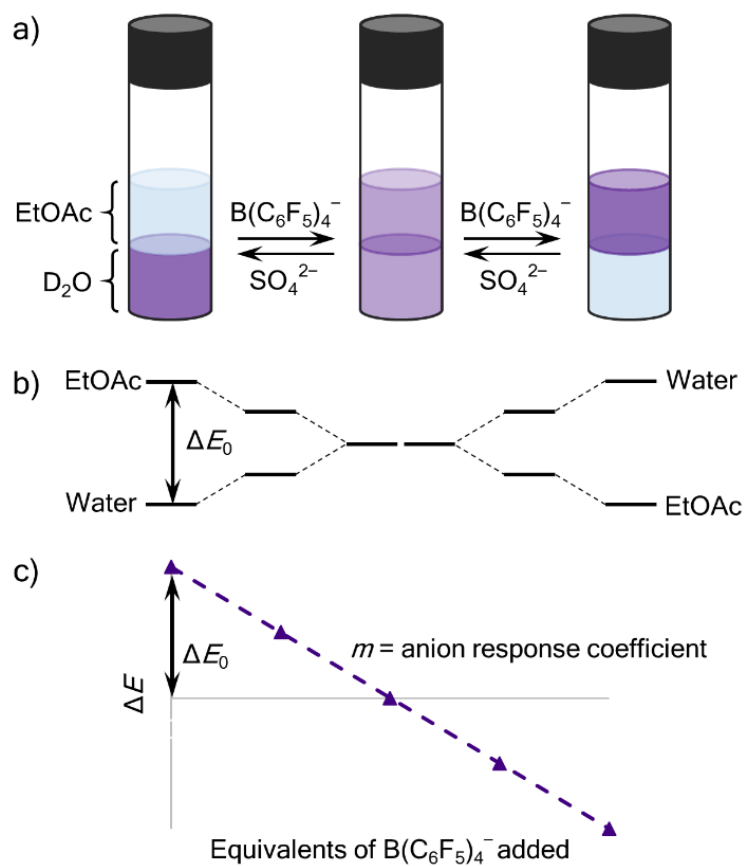

Figure 3. (a,b) Cages partition between two phases as a function of the difference between $E_{\mathrm{EtOAc}}$ and $E_{\text {water }}(\Delta E)$, which depends upon the amounts of the two anions present. (c) There is a linear relationship between $\Delta E$ and the amount of $\mathrm{B}\left(\mathrm{C}_{6} \mathrm{~F}_{5}\right)_{4}{ }^{-}$added to the system; the slope $(\mathrm{m})$ quantifies the anion responsivity of each cage.

where $n_{\text {water }}$ and $n_{\text {EtOAc }}$ are the amounts of cage in the water and EtOAc layers, respectively.

Initially, when no $\mathrm{B}\left(\mathrm{C}_{6} \mathrm{~F}_{5}\right)_{4}{ }^{-}$had been added and the cage resided exclusively in the water layer as the $\mathrm{SO}_{4}{ }^{2-}$ salt, this energy gap is defined as $\Delta E_{\mathrm{o}}$ (Figure $3 \mathrm{~b}$ ). Because cage solvation in water is initially more favourable than cage solvation in EtOAc, $\Delta E_{\mathrm{o}}$ is positive. As $\mathrm{B}\left(\mathrm{C}_{6} \mathrm{~F}_{5}\right)_{4}{ }^{-}$is added to the system, $\Delta E$ decreases. Beyond the equivalence point, where $E_{\text {water }}=E_{\mathrm{EtOAc}}$, the cage progressively partitions into EtOAc from a water layer of equal volume, as $\Delta E$ becomes negative. The parameter $\Delta E$ thus quantifies the degree to which the addition of hydrophobic anions to the system renders cage solvation in EtOAc progressively more favourable.

Furthermore, we found a linear relationship between $\Delta E$ and $x$, the amount of $\left.\mathrm{B}_{(} \mathrm{C}_{6} \mathrm{~F}_{5}\right)_{4}{ }^{-}$added to the system (Figure 3c). The slope of this line, $m$, is defined as the anion response coefficient and describes the amount by which $\Delta E$ changes per equivalent of $\mathrm{B}\left(\mathrm{C}_{6} \mathrm{~F}_{5}\right)_{4}{ }^{-}$added to the system.

When considering the phase transfer of cages $\mathbf{1}^{\mathbf{8 +}}, \mathbf{2}^{\mathbf{8 +}}$, or $3^{16+}$ in isolation, $\Delta E_{\mathrm{o}}\left(3^{16+}\right)<\Delta E_{\mathrm{o}}\left(\mathbf{2}^{8+}\right)<\Delta E_{\mathrm{o}}\left(\mathbf{1}^{8+}\right)$. These values relate to the inherent hydrophobicity of the cage cations. As cage hydrophobicity increases, $E_{\text {water }}$ is higher and $E_{\mathrm{EtOAc}}$ is lower, leading to a decrease in $\Delta E_{0}$. The hydrophobicity of a cage cation depends upon the charge density of the cage and the nature of the subcomponents from which the cage is assembled. Despite the higher charge of cage $3^{\mathbf{1 6 +}}$, the charge density of this cage is lower than the charge densities of cages $\mathbf{1}^{\mathbf{8 +}}$ or $\mathbf{2}^{\mathbf{8 +}}$, because the cubic cage 

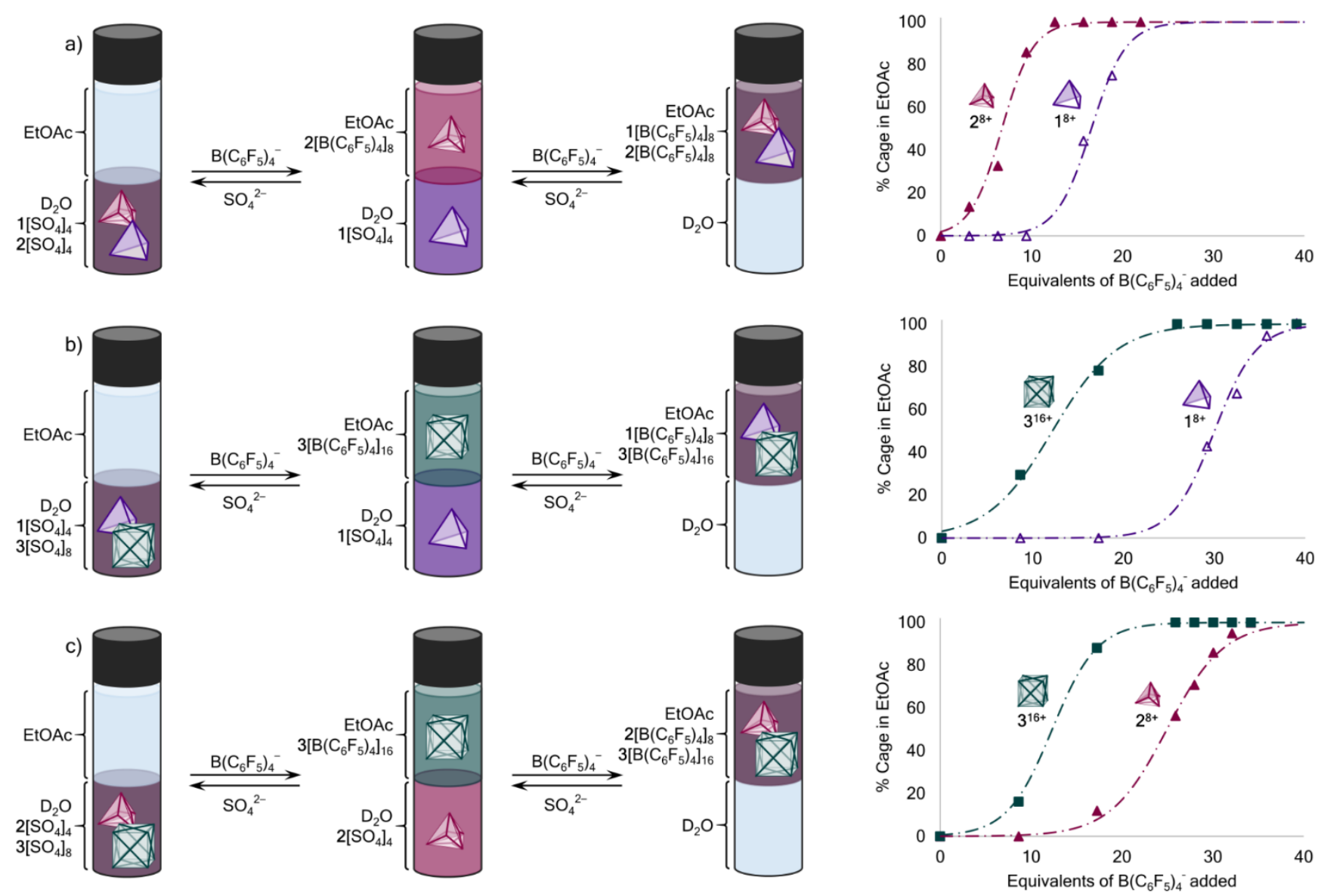

Figure 4. Phase transfer of (a) cages $\mathbf{1}^{8+}$ and $\mathbf{2}^{8+}$; (b) cages $\mathbf{1}^{8+}$ and $3^{16+}$; (c), cages $\mathbf{2}^{8+}$ and $3^{16+}$. Monitoring was carried out by sliceselective ${ }^{1} \mathrm{H}$ NMR. Data were fit to equation (1).

has approximately 3 times the surface area, and 7 times the volume, of the tetrahedral cages (see SI section $\mathrm{S}_{7}$ ). Furthermore, the charge densities of cages $\mathbf{1}^{8+}$ and $\mathbf{2}^{8+}$ are comparable. Cage $3^{16+}$, with the lowest charge density and six porphyrin faces, is thus more hydrophobic than cages $\mathbf{1}^{\mathbf{8 +}}$ or $\mathbf{2}^{\mathbf{8 +}}$. Cage $\mathbf{2}^{\mathbf{8 +}}$, with four triazine faces, is in turn more hydrophobic than cage $\mathbf{1}^{8+}$, which has twelve pendant glyceryl groups.

These values of $\Delta E_{\mathrm{o}}$ can be understood intuitively in terms of their charge density and the solvent exposure of their aromatic edges or faces. Their relative ordering, however, appeared initially to contradict the observation that cage $3^{16+}$ required more equivalents of $\mathrm{B}\left(\mathrm{C}_{6} \mathrm{~F}_{5}\right)_{4}{ }^{-}$than cages $\mathbf{1}^{8+}$ or $\mathbf{2}^{8+}$ in order to achieve complete phase transfer into EtOAc (Figure 2a). This apparent discrepancy occurs because cage $3^{16+}$ has a smaller anion response coefficient than cages $\mathbf{1}^{8+}$ and $\mathbf{2}^{8+}:|m|\left(3^{16+}\right)<|m|\left(\mathbf{1}^{8+}\right)<$ $|m|\left(\mathbf{2}^{8+}\right)$.

Because cubic cage $3^{16+}$ carries twice the positive charge of tetrahedral cages $\mathbf{1}^{8+}$ and $\mathbf{2}^{8+}$, twice as many $\mathrm{SO}_{4}{ }^{2-}$ counterions are associated with 3 than with $\mathbf{1}^{8+}$ or $\mathbf{2}^{8+}$. When $\mathrm{B}\left(\mathrm{C}_{6} \mathrm{~F}_{5}\right)_{4}{ }^{-}$anions were added to the system, competition from these more numerous $\mathrm{SO}_{4}{ }^{2-}$ anions ultimately causes cage $3^{16+}$ to be less susceptible to the addition of hydrophobic anions than cages $\mathbf{1}^{\mathbf{8}_{+}}$and $\mathbf{2}^{\mathbf{8}_{+}}$. Conversely, cages $\mathbf{1}^{8+}$ and $\mathbf{2}^{8+}$ carry the same charge and are initially associated with the same number of $\mathrm{SO}_{4}{ }^{2-}$ counterions. Our model thus quantified the intuitive expectation that cage $\mathbf{2}^{8+}$ (the more hydrophobic tetrahedron) should be more susceptible than cage $\mathbf{1}^{8+}$ to the addition of $\mathrm{B}\left(\mathrm{C}_{6} \mathrm{~F}_{5}\right)_{4}{ }^{-}$anions.

Sequential phase transfer of individual cages from a mixture. As discussed above, the phase transfer behaviors of cages $\mathbf{1}^{8+}, \mathbf{2}^{8+}$, and $3^{16+}$ can be defined by the parameters $\Delta E$ and $m$, with values characteristic of each cage. Consequently, we designed a series of phase transfer experiments to study how competition among different cage species would shape the transfer responses of each individual cage species within a mixture (Figure 4 ). In these mixed-cage phase transfer experiments, two different cages $\left(\mathbf{1}^{8+}+\mathbf{2}^{8+}, \mathbf{1}^{8+}+3^{16+}\right.$, and $\left.\mathbf{2}^{8+}+3^{16+}\right)$ were initially dissolved together in the $\mathrm{D}_{2} \mathrm{O}$ layer. Each cage was present at the same concentration $(0.5 \mathrm{mM})$. Upon the addition of hydrophobic anions, only one cage species was observed to pair with $\mathrm{B}\left(\mathrm{C}_{6} \mathrm{~F}_{5}\right)_{4}^{-}$and preferentially transfer into the EtOAc layer. Only after the first cage species was approaching complete transfer into EtOAc did the second cage species begin to transfer phase. Separation of each combination of two cage species thus occurred in all three experiments. When cages $\mathbf{1}^{8+}$ and $3^{16+}$ were combined, for example, the maximum separation achieved was calculated to be $90.9 \%$. In all cases, the second cage was subsequently driven into the EtOAc layer by adding more $\mathrm{B}\left(\mathrm{C}_{6} \mathrm{~F}_{5}\right)_{4}^{-}$. This process was fully reversible upon the addition of $\mathrm{SO}_{4}{ }^{2-}$. 
a)

Increasing stabilisation of cages in water

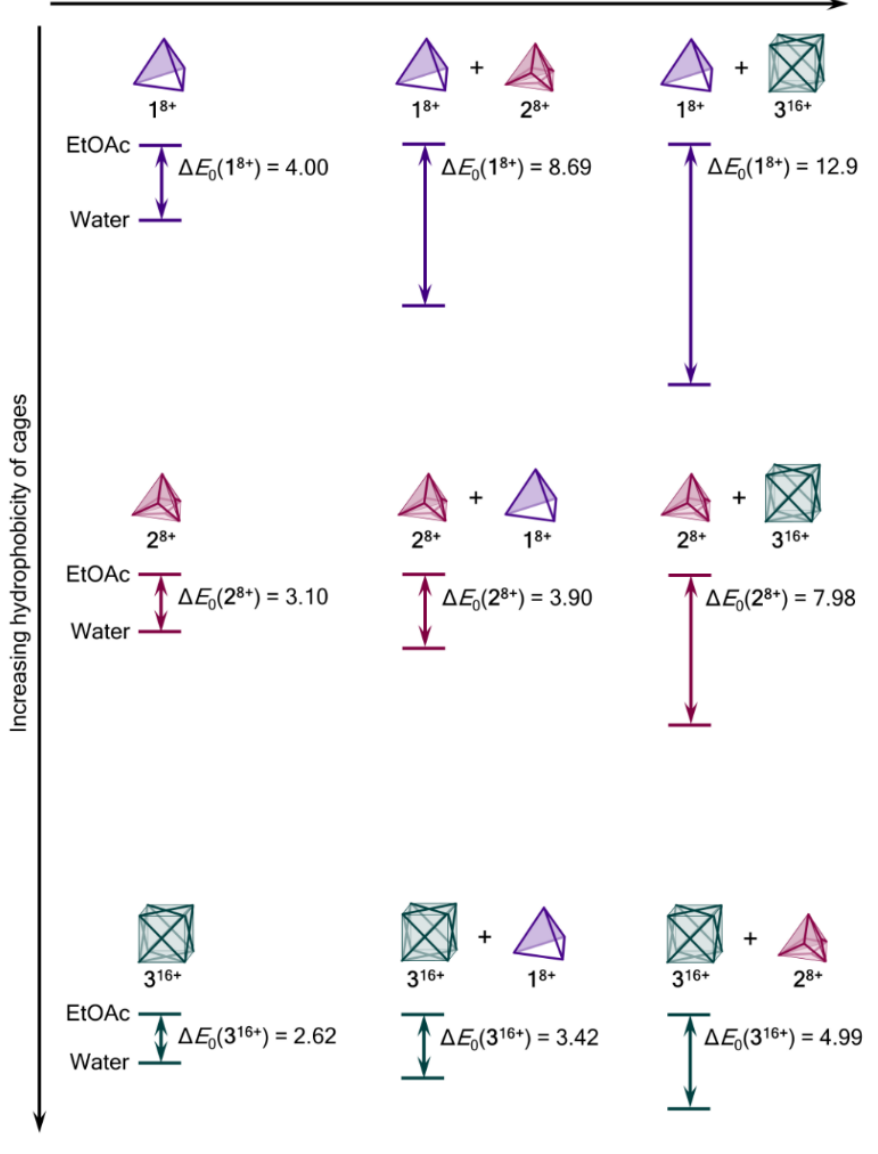

b) Single-cage systems:

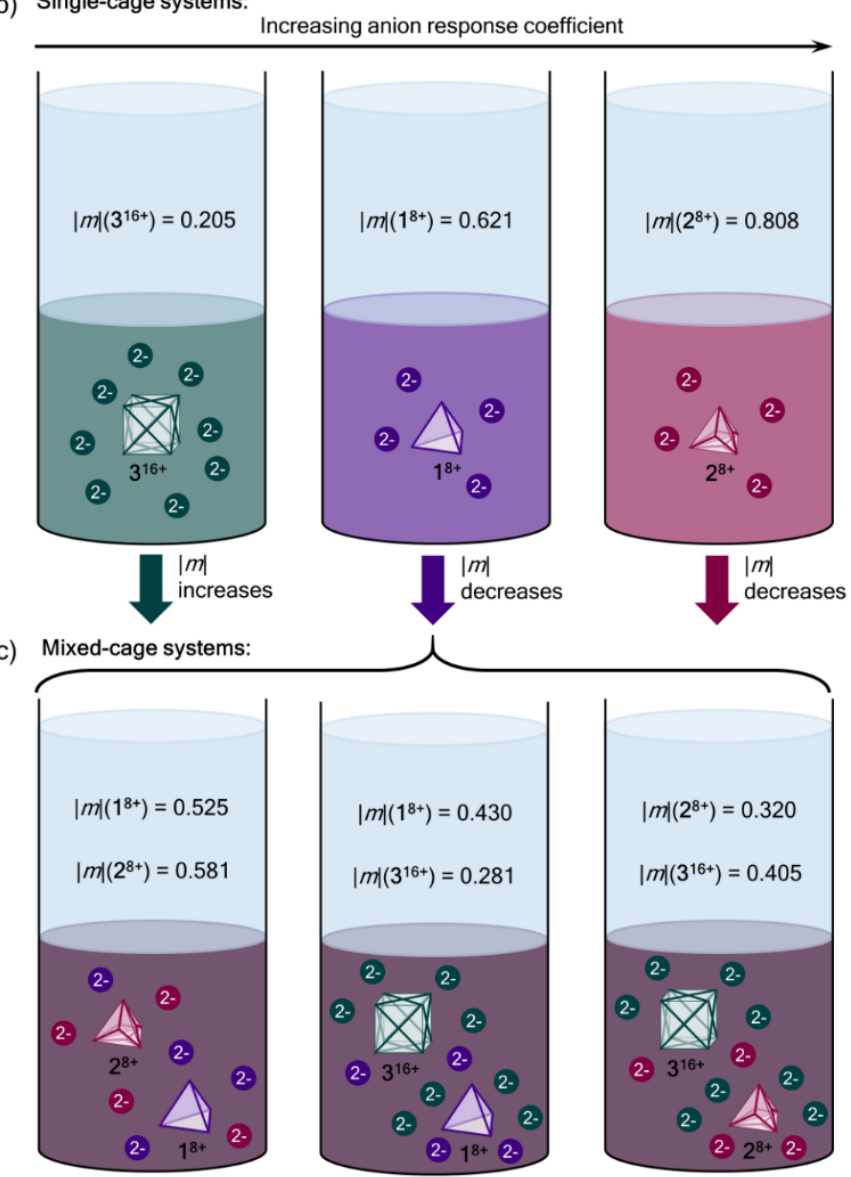

Figure 5. (a) Summary of the $\Delta E_{\mathrm{o}}$ values (in units of $k T$ ) for each cage in the presence and absence of other cage species. Within each row, the initial EtOAc layers contain no solutes, rendering the initial $E_{\mathrm{EtOAc}}$ levels equivalent. (b,c) Summary of the $m$ values for each cage (in units of $k T$ ) in the presence and absence of other cage species. Due to the lower charge density of cage $3^{\mathbf{1 6 +}}$, we hypothesize that the effective sulfate concentration around cage $3^{\mathbf{1 6 +}}$ is lowered when it is combined with cages $\mathbf{1}^{\mathbf{8 +}}$ or $\mathbf{2}^{\mathbf{8 +}}$.

The individual transfer profiles of cages $1^{8+}, 2^{8+}$, and $3^{16+}$ were perturbed by the presence of other cage species. When dissolved together, cages $\mathbf{1}^{8+}$ and $\mathbf{2}^{8+}$ required more anions to achieve complete transfer than they required in isolation. Conversely, cage $3^{\mathbf{1 6 +}}$ required fewer anions. As was observed when the cages were investigated in isolation, cage $\mathbf{2}^{\mathbf{8}+}$ required fewer anions to achieve complete transfer than cage $\mathbf{1}^{\mathbf{8}+}$, which in turn required fewer anions than cage $3^{16+}$. Based on the amounts of $B\left(C_{6} F_{5}\right)_{4}{ }^{-}$required for $50 \%$ transport of each cage in isolation (Figure $2 \mathrm{a}$ ), we expected cage $\mathbf{2}^{\mathbf{8 +}}$ to transfer into EtOAc before cage $\mathbf{1}^{\mathbf{8 +}}$, followed by cage $3^{\mathbf{1 6 +}}$. As expected, cage $\mathbf{2}^{\mathbf{8 +}}$ preferentially transferred into EtOAc before cage $\mathbf{1}^{\mathbf{8}}$. We were initially surprised to observe, however, that cage $3^{16+}$ transferred into EtOAc before either cages $\mathbf{1}^{8+}$ or $\mathbf{2}^{8+}$.

Thermodynamic model describing the sequential phase transfer of mixed-cage systems. In order to quantitatively describe the phase transfer behaviours of cages $\mathbf{1}^{8+}, \mathbf{2}^{8+}$, and $3^{16+}$

in the presence of other cage species, we calculated the values of $\Delta E_{\mathrm{o}}$ and $m$ for each cage within each sequential phase transfer experiment. The thermodynamic model described above was thus used to analyse the sliceselective ${ }^{1} \mathrm{H}$ NMR data from the three competition experiments $\left(1^{8+}+2^{8+}, 1^{8+}+3^{16+}\right.$, and $\left.2^{8+}+3^{16+}\right)$. The values of
$\Delta E_{\mathrm{o}}$ and $m$ that we obtained are summarised in Figure 5 and are discussed below.

For all cages, $\Delta E_{\mathrm{o}}$ was observed to increase when other cage species were present (Figure $5 \mathrm{a}$ ). Because all the components in these systems started in the water layer, the EtOAc layers should have the same initial composition across all phase transfer experiments. We therefore assume that, before the addition of anions, $E_{\mathrm{EtOAc}}$ for each cage was unaffected by the presence or absence of other species. In the presence of other cage species, we thus deduce that the increased values of $\Delta E_{0}$ for each cage were the result of lowered $E_{\text {water }}$ energy states. This effect can be understood as follows: when different cages are present together, each cage species is stabilised in water by the sulfate counteranions from the other species. The extent of this stabilisation is dependent on the identities of both cages present in solution. Cage $3^{16+}$ was observed to stabilise cages $\mathbf{1}^{8+}$ and $\mathbf{2}^{8+}$ in water to a greater degree than cage $2^{8+}$ stabilised cages $1^{8+}$ and $3^{16+}$, and cage $1^{8+}$ was found to have the smallest effect on the aqueous stabilisation of either of the other species.

The anion response coefficient for each cage, however, either increased or decreased depending on the identity of the other cage species present. For cages $\mathbf{1}^{8+}$ and $\mathbf{2}^{\mathbf{8 +}}$, $|m|$ was smaller when other species were present, mean- 
ing that the cages became less responsive to the addition of hydrophobic anions. Conversely, $|m|$ for cubic cage $3^{16+}$ became larger when other species were present; $3^{16+}$ thus became more responsive to the addition of $\mathrm{B}_{(}\left(\mathrm{C}_{6} \mathrm{~F}_{5}\right)_{4}^{-}$.

Determining the parameters $\Delta E_{\mathrm{o}}$ and $m$, as summarized in Figure 5, has allowed us to formulate an explanation to describe the transfer behaviour of these cages. When comparing cages $\mathbf{1}^{8+}$ and $\mathbf{2}^{8+}$, both cages bear the same charge, but cage $\mathbf{2}^{8+}$ is more hydrophobic (smaller $\Delta E_{\mathrm{o}}$ ), more responsive to the addition of $\mathrm{B}_{(}\left(\mathrm{C}_{6} \mathrm{~F}_{5}\right)_{4}{ }^{-}$(larger $\left.|m|\right)$, and therefore transferred into EtOAc more readily than cage $\mathbf{1}^{8+}$. When combined with other cage species, cages $\mathbf{1}^{\mathbf{8 +}}$ or $\mathbf{2}^{8+}$ were stabilised in the water layer by the higher $\mathrm{SO}_{4}{ }^{2-}$ concentration, and they became less responsive to the addition of $\mathrm{B}\left(\mathrm{C}_{6} \mathrm{~F}_{5}\right)_{4}^{-}(|\mathrm{m}|$ decreased $)$. Cage $3^{16+}$ has twice the charge, and thus twice the number of $\mathrm{SO}_{4}{ }^{2-}$ counterions, but is more intrinsically hydrophobic (smaller $\Delta E_{0}$ ) than cages $\mathbf{1}^{8+}$ or $\mathbf{2}^{8+}$. Because cage $3^{16+}$ has twice the number of $\mathrm{SO}_{4}{ }^{2-}$ counterions, $3^{16+}$ is less responsive to the addition to the addition of $\left.\mathrm{B}_{(} \mathrm{C}_{6} \mathrm{~F}_{5}\right)_{4}^{-}$(smaller $|m|$ ) than either $\mathbf{1}^{8+}$ or $\mathbf{2}^{8+}$. When combined with other cage species, the $\mathrm{SO}_{4}{ }^{2-}$ counterions from cage $3^{16+}$ were pulled away by cages $\mathbf{1}^{8+}$ or $\mathbf{2}^{8+}$ because their charge density is higher. Consequently, cage $3^{16+}$ became more responsive to the addition of $\left.\mathrm{B}_{(} \mathrm{C}_{6} \mathrm{~F}_{5}\right)_{4}{ }^{-}(|\mathrm{m}|$ increased) in the presence of $\mathbf{1}^{8+}$ or $\mathbf{2}^{8+}$. The combination of these effects (intrinsic hydrophobicity and anion responsivity) resulted in cage $3^{16+}$ undergoing phase transfer before cages $\mathbf{1}^{8+}$ or $\mathbf{2}^{8^{++}}$.

Implications and applications of sequential phase transfer. Because each cage species perturbed the transfer profile of other cage species within a mixture, we inferred that we could use one cage species as a stimulus to trigger the phase transfer of another (Figure 6a). We thus prepared a biphasic system containing EtOAc $(200 \mu \mathrm{L})$ and cage $\mathbf{1}\left[\mathrm{SO}_{4}\right]_{4}(0.10 \mu \mathrm{mol})$ in $\mathrm{D}_{2} \mathrm{O}(200 \mu \mathrm{L})$. B $\left(\mathrm{C}_{6} \mathrm{~F}_{5}\right)_{4}^{-}{ }^{-}(13$ equiv) was then added, triggering the phase transfer of cage $\mathbf{1}^{8+}$ from $\mathrm{D}_{2} \mathrm{O}$ into EtOAc; the original $\mathrm{SO}_{4}{ }^{2-}$ counterions from cage $\mathbf{1}^{8+}$ remained in the $\mathrm{D}_{2} \mathrm{O}$ layer. Cage ${ }_{3}\left[\mathrm{SO}_{4}\right]_{8}(0.10 \mu \mathrm{mol})$ was then added to the system, causing cage $\mathbf{1}^{8+}$ to transfer from EtOAc back into the $\mathrm{D}_{2} \mathrm{O}$ layer. As with the other phase transfer processes described herein, this transformation was governed by anion exchange: from $\left.\mathrm{B}_{(} \mathrm{C}_{6} \mathrm{~F}_{5}\right)_{4}{ }^{-}$to $\mathrm{SO}_{4}{ }^{2-}$ for cage $\mathbf{1}^{8+}$ and from $\mathrm{SO}_{4}{ }^{2-}$ to $\mathrm{B}\left(\mathrm{C}_{6} \mathrm{~F}_{5}\right)_{4}^{-}$for cage $3^{16+}$. Significantly, this experiment demonstrates that the physical location of a cage species can be controlled through the addition of another cage.

Finally, we used the sequential phase transfer of cages $2^{8+}$ and $3^{16+}$ to separate a mixture of organic molecules (Figure 6b). Cyclooctadiene (A) and coronene (B) were chosen as prospective guest molecules because they have been previously shown to bind strongly and in slow exchange within cages $\mathbf{2}^{8+}$ and $3^{16+}$, respectively. ${ }^{14,15} \mathbf{A} \subset \mathbf{2}^{8+}$ and $\mathbf{B}_{3} \subset 3^{3^{16+}}$ were combined in $\mathrm{D}_{2} \mathrm{O}$, and $\mathrm{B}\left(\mathrm{C}_{6} \mathrm{~F}_{5}\right)_{4}{ }^{-}(18$ equiv) was added to trigger the phase transfer of $\mathbf{B}_{3} \subset 3^{16+}$ into EtOAc. Because cages $\mathbf{2}^{8+}$ and $3^{16+}$ are face-capped, their cargoes $\mathbf{A}$ and $\mathbf{B}$ become kinetically trapped upon encapsulation in polar solvents. $15,17,23$ This effect allows cages $2^{8+}$ and $3^{16+}$ to transport their molecular cargoes as they move between immiscible liquid layers. Using the
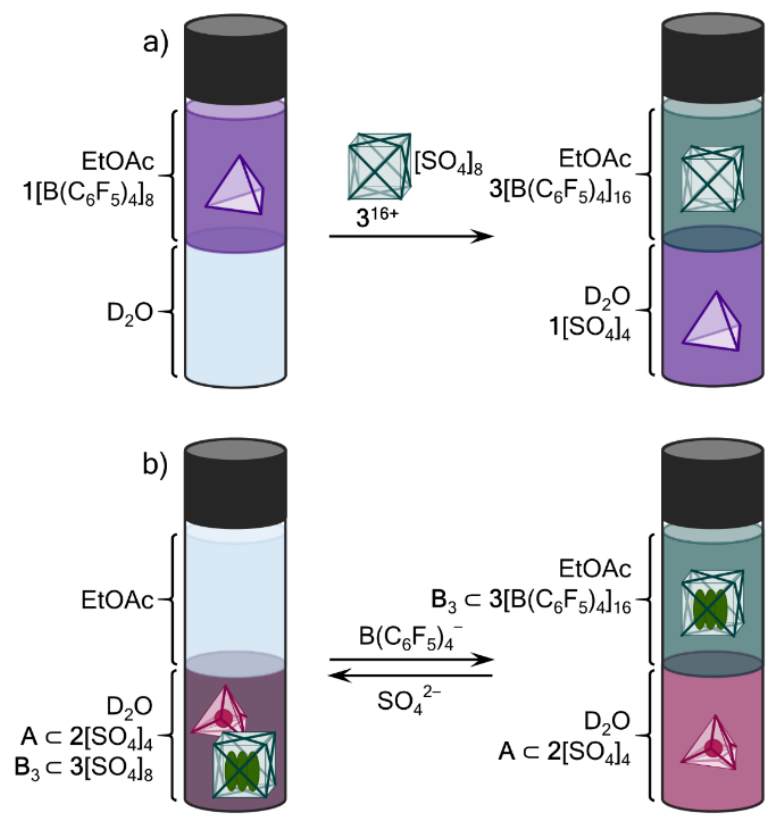

Figure 6. (a) Upon the addition of cage $3\left[\mathrm{SO}_{4}\right]_{8}$ to a biphasic system in which cage $\left.1\left[\mathrm{~B} \mathrm{C}_{6} \mathrm{~F}_{5}\right)_{4}\right]_{8}$ is dissolved in the EtOAc layer, $\mathbf{1}^{8+}$ was observed to migrate to the $\mathrm{D}_{2} \mathrm{O}$ layer. (b) Upon

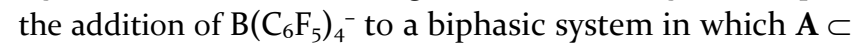
${ }_{2}\left[\mathrm{SO}_{4}\right]$ and $\mathbf{B}_{3} \subset{ }_{3}\left[\mathrm{SO}_{3}\right]$ were dissolved in the $\mathrm{D}_{2} \mathrm{O}$ layer, $\mathbf{B}_{3}$ $\subset_{3}\left[\mathrm{SO}_{3}\right]$ was observed to transfer into the EtOAc layer.

sequential phase transfer of cages $2^{8+}$ and $3^{16+}$, we thus separated the two cages and their respective cargoes, $\mathbf{A}$ and $\mathbf{B}$. Notably, in the sequential phase transfer of cages $2^{8+}$ and $3^{16+}$ (in which the cages were filled with solvent molecules) and the sequential phase transfer of cages $\mathbf{A} \subset$ $2^{8+}$ and $\mathbf{B}_{3} \subset 3^{16+}$ (in which the cages were filled with guests that bind strongly and in slow exchange), both experiments required the same number of anion equivalents to separate the two cages ( 18 equiv of $\mathrm{B}\left(\mathrm{C}_{6} \mathrm{~F}_{5}\right)_{4}{ }^{-}$), indicating that the presence and identities of guests within the cage cavities did not measurably alter the thermodynamics of the system.

\section{CONCLUSION}

Using hydrophobic or hydrophilic anions as stimuli, coordination cages $\mathbf{1}^{8+}, \mathbf{2}^{8+}$, and $3^{16+}$ were shown to transfer between water and EtOAc over 11 times. When cages $\mathbf{2}^{8+}$ and $3^{16+}$ were combined, the preferential transfer of cage $3^{16+}$ before cage $\mathbf{2}^{8+}$ resulted in the separation of their molecular cargoes. Building upon these results, additional complexity and functionality may be attained by combining three or more different cage species of varying sizes, with each cage species encapsulating a different guest. ${ }^{24-28}$ Upon sequential transfer of each host-guest complex into EtOAc, the separated cargoes could then be collected. The cage could, for instance, release its cargo upon opening. As shown by Zhang et al., an opened cage may subsequently be regenerated..$^{20}$ Notably, the use of this technique would not require thermal energy, and would generate only re-usable salts as a by-product. Our method is significant in the context of chemical separations, ${ }^{23,29-32}$ which remain the most energy-intensive processes in industry. Thermal approaches such as distillation, for in- 
stance, consume nearly half of the total industrial energy budget in the US. 33 Indeed, the economic and environmental costs of chemical separation are equivalent to those imposed by half the country's transportation sector. 34

Furthermore, the thermodynamic model developed herein constitutes a new tool to quantify the hydrophobicity of coordination cages and other molecular species that transfer between phases. This model may be extensible to molecular transport across cell membranes, ${ }^{35}$ across membranes for industrial separations, ${ }^{36}$ and in energy storage materials. ${ }^{37}$ This study thus serves as an experimental and theoretical foundation to begin developing energy-efficient separations technologies based on the phase transfer of coordination cages and their cargoes.

\section{ASSOCIATED CONTENT}

\section{Supporting Information}

Synthetic procedures and characterization for cages $\mathbf{1}^{\mathbf{8 +}}, \mathbf{2}^{\mathbf{8 +}}$, and $3^{16+}$. UV-vis calibration and stability data for cages $\mathbf{1}^{8+}$, $\mathbf{2}^{8+}$, and $3^{\mathbf{1 6 +}}$. Anion titrations, monitored by UV-vis spectrophotometry. Approximation of the charge densities of cages $1^{8+}, 2^{8+}$, and $3^{16+}$. Automation of slice-selective NMR acquisition. Phase transfer cycles of cages $\mathbf{1}^{8+}, \mathbf{2}^{8+}$, and $3^{16+}$, monitored by slice-selective ${ }^{1} \mathrm{H}$ NMR. Sequential phase transfer of mixed-cage systems. Thermodynamic model of single- and mixed-cages systems. Phase transfer of cage $\mathbf{1}^{8+}$ driven by the addition of cage $3^{\mathbf{1 6 +}}$. Separation of cyclooctadiene $\subset \mathbf{2}^{\mathbf{8 +}}$ from $\mathrm{B}_{3} \subset 3^{16+}$.

This material is available free of charge via the Internet at http://pubs.acs.org.

\section{AUTHOR INFORMATION}

\section{Corresponding Author}

Email: jrn34@cam.ac.uk

\section{Author Contributions}

All authors have given approval to the final version of the manuscript.

\section{Funding Sources}

This work was supported by the UK Engineering and Physical Sciences Research Council (EPSRC EP/Po27067/1) and the European Research Council (ERC 695009).

\section{Notes}

The authors declare no competing financial interests.

\section{ACKNOWLEDGMENT}

We thank Ben Pilgrim for experimental suggestions, and Larissa von Krbek for discussions regarding the thermodynamic model.

\section{REFERENCES}

(1) Fujita, M.; Oguro, D.; Miyazawa, M.; Oka, H.; Yamaguchi, K.; Ogura, K. Nature 1995, 378, 469-471.

(2) Cullen, W.; Misuraca, M. C.; Hunter, C. A.; Williams, N. H.; Ward, M. D. Nat. Chem. 2016, 8, 231-236.
(3) Rizzuto, F. J.; Nitschke, J. R. Nat. Chem. 2017, 9, 903-908.

(4) Holloway, L. R.; Bogie, P. M.; Hooley, R. J. Dalt. Trans. 2017, 46, 14719-14723.

(5) Chen, L.-J.; Yang, H.-B.; Shionoya, M. Chem. Soc. Rev. 2017, 46, 2555-2576.

(6) Beaudoin, D.; Rominger, F.; Mastalerz, M. Angew. Chemie Int. Ed. 2017, 56, 1244-1248.

(7) Bhat, I. A.; Jain, R.; Siddiqui, M. M.; Saini, D. K.; Mukherjee, P. S. Inorg. Chem. 2017, 56, 5352-5360.

(8) Wang, W.; Wang, Y.-X.; Yang, H.-B. Chem. Soc. Rev. 2016, 45, 2656-2693.

(9) Langton, M. J.; Keymeulen, F.; Ciaccia, M.; Williams, N. H.; Hunter, C. A. Nat. Chem. 2017, 9, 426-430.

(10) Pilgrim, B. S.; Roberts, D. A.; Lohr, T. G.; Ronson, T. K.; Nitschke, J. R. Nat. Chem. 2017, 9, 1276-1281.

(11) Clever, G. H.; Punt, P. Acc. Chem. Res. 2017, 50, 2233-2243.

(12) Sommer, F.; Marcus, Y.; Kubik, S. ACS Omega 2017, 2, 3669-368o.

(13) Bolliger, J. L.; Belenguer, A. M.; Nitschke, J. R. Angew. Chemie - Int. Ed. 2013, 52, 7958-7962.

(14) Meng, W.; Breiner, B.; Rissanen, K.; Thoburn, J. D.; Clegg, J. K.; Nitschke, J. R. Angew. Chemie - Int. Ed. 2011, 50, 34793483.

(15) Bolliger, J. L.; Ronson, T. K.; Ogawa, M.; Nitschke, J. R. J. Am. Chem. Soc. 2014, 136, 14545-14553.

(16) Yi, S.; Brega, V.; Captain, B.; Kaifer, A. E. Chem. Commun. 2012, 48, 10295.

(17) Percástegui, E. G.; Mosquera, J.; Nitschke, J. R. Angew. Chemie - Int. Ed. 2017, 56, 9136-9140.

(18) Ghosh, S. K.; Ojeda, A. S.; Guerrero-Leal, J.; Bhuvanesh, N.; Gladysz, J. A. Inorg. Chem. 2013, 52, 9369-9378.

(19) Ganzmann, C.; Gladysz, J. A. Chem. - A Eur. J. 20o8, 14, 5397-5400.

(20) Zhang, D.; Ronson, T. K.; Mosquera, J.; Martinez, A.; Nitschke, J. Angew. Chemie Int. Ed. 2018, No. Figure 1, 37173721.

(21) Pöppler, A. C.; Frischkorn, S.; Stalke, D.; John, M. Chem. Phys. Chem. 2013, 14, 3103-3107.

(22) Niklas, T.; Stalke, D.; John, M. Chem. Commun. 2015, 51, 1275-1277.

(23) Grommet, A. B.; Nitschke, J. R. J. Am. Chem. Soc. 2017, 139, 2176-2179.

(24) Yamashina, M.; Akita, M.; Hasegawa, T.; Hayashi, S.; Yoshizawa, M. Sci. Adv. 2017, 3, 2-8.

(25) Turega, S.; Whitehead, M.; Hall, B. R.; Meijer, A. J. H. M.; Hunter, C. A.; Ward, M. D. Inorg. Chem. 2013, 52, 1122-1132.

(26) Huerta, E.; Serapian, S. A.; Santos, E.; Cequier, E.; Bo, C.; de Mendoza, J. Chem. - A Eur. J. 2016, 22, 13496-13505.

(27) Fang, Y.; Murase, T.; Sato, S.; Fujita, M. J. Am. Chem. Soc. 2013, 135, 613-615.

(28) Fang, Y.; Murase, T.; Fujita, M. Chem. - An Asian J. 2014, 9, 1321-1328.

(29) Zhang, G.; Mastalerz, M. Chem. Soc. Rev. 2o14, 43, 19341947.

(30) Moyer, B. A.; Custelcean, R.; Hay, B. P.; Sessler, J. L.; Bowman-James, K.; Day, V. W.; Kang, S.-O. Inorg. Chem. 2013, 52, 3473-3490.

(31) Liu, Z.; Frasconi, M.; Lei, J.; Brown, Z. J.; Zhu, Z.; Cao, D.; Iehl, J.; Liu, G.; Fahrenbach, A. C.; Botros, Y. Y.; et al. Nat. Commun. 2013, 4, 1855-1859.

(32) Grommet, A. B.; Bolliger, J. L.; Browne, C.; Nitschke, J. R. Angew. Chemie - Int. Ed. 2015, 54, 15100-15104.

(33) Sholl, D. S.; Lively, R. P. Nature 2016, 532, 435-437.

(34) Lively, R. P.; Sholl, D. S. Nat. Mater. 2017, 16, 276-279.

(35) Giacomini, K. M.; Huang, S.-M.; Tweedie, D. J.; Benet, L. Z.; Brouwer, K. L. R.; Chu, X.; Dahlin, A.; Evers, R.; Fischer, V.; Hillgren, K. M.; et al. Nat. Rev. Drug Discov. 2010, 9, 215236.

(36) Marchetti, P.; Jimenez Solomon, M. F.; Szekely, G.; Livingston, A. G. Chem. Rev. 2014, 114, 10735-10806.

(37) Arora, P.; Zhang, Z. Chem. Rev. 2004, 104, 4419-4462. 



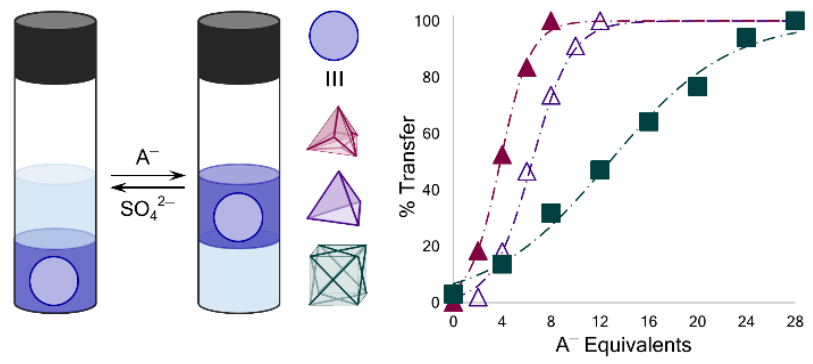

